\title{
Effect of Different Aging Methods on the Formation of Aroma Volatiles in Beef Strip Loins
}

\author{
Dongheon Lee ${ }^{1,+}+\mathbb{D}$, Hyun Jung Lee ${ }^{1,+}$, Ji Won Yoon ${ }^{1}$, Minsu Kim ${ }^{1}$ and Cheorun Jo ${ }^{1,2, *(\mathbb{C}}$ \\ 1 Center for Food and Bioconvergence, Department of Agricultural Biotechnology, and Research Institute of \\ Agriculture and Life Science, Seoul National University, Seoul 08826, Korea; sptails@snu.ac.kr (D.L.); \\ leehj0113@gmail.com (H.J.L.); ony0114@gmail.com (J.W.Y.); hoptop@snu.ac.kr (M.K.) \\ 2 Institute of Green Bio Science and Technology, Seoul National University, Pyeongchang 25354, Korea \\ * Correspondence: cheorun@snu.ac.kr; Tel.: +82-2-880-4804 \\ + These authors contributed equally to this work.
}

Citation: Lee, D.; Lee, H.J.; Yoon,

J.W.; Kim, M.; Jo, C. Effect of Different Aging Methods on the Formation of Aroma Volatiles in Beef Strip Loins. Foods 2021, 10, 146. https://doi.org/ $10.3390 /$ foods 10010146

Received: 14 December 2020 Accepted: 10 January 2021 Published: 12 January 2021

Publisher's Note: MDPI stays neutral with regard to jurisdictional clai$\mathrm{ms}$ in published maps and institutional affiliations.

Copyright: $(2021$ by the authors. Licensee MDPI, Basel, Switzerland. This article is an open access article distributed under the terms and conditions of the Creative Commons Attribution (CC BY) license (https:// creativecommons.org/licenses/by/ $4.0 /)$.

\begin{abstract}
This study investigated the effects of different aging methods on the changes in the concentrations of aroma volatiles of beef. One half $(n=15)$ of the beef strip loins were dry-aged, and the other half were wet-aged, and both aging processes continued for 28 days. The aroma volatiles from dry- and wet-aged samples were analyzed at seven-day intervals ( $n=3$ for each aging period). As the aging period increased, dry-aged beef showed higher concentrations of volatile compounds than those in wet-aged beef $(p<0.05)$. Most changes in the concentrations of aroma volatiles of dry-aged beef were associated with propanal, 2-methylbutanal, 2-methylpropanal, 1-butanamine, trimethylamine, 2-methyl-2-propanethiol, and ethyl propanoate, which were mainly produced by lipid oxidation and/or microbial activity (e.g., proteolysis and lipolysis) during the dry aging period. Therefore, we suggest that the differences in aroma between dry- and wet-aged beef could result from increased lipid oxidation and microbial activity in dry-aged beef possibly owing to its ambient exposure to oxygen.
\end{abstract}

Keywords: dry aging; wet aging; aroma volatiles; aging periods

\section{Introduction}

Aging is the process of storing meat in a controlled environment for a certain period to increase the palatability of meat [1]. Aging can be especially effective for beef with low consumer preference as value addition. There are two forms of aging: wet and dry [2]. In wet aging, meat is vacuum-packaged and stored in a refrigerated condition [1]. On the other hand, dry aging involves holding the meat unpacked in the open air [3]. Dry- and wet-aged beef are under different environmental factors, i.e., dry-aged beef is influenced by not only temperature but also relative humidity and air flow, and is exposed to oxygen, while wet-aged beef is in anaerobic conditions. Due to the different aging conditions, many studies reported different physicochemical attributes between dry- and wet-aged beef $[2,4]$. Furthermore, the flavor of dry- and wet-aged beef is known to be discriminable. In general, dry-aged beef has more beefy, roasted, and nutty flavor, while wet-aged beef has a more intense sour, metallic, and bloody flavor [4].

Flavor is important for determining eating quality of meat, which affects consumer preferences [5]. Flavor is defined as the combination of taste and aroma and is attributed to different flavor compounds [6]. Flavor compounds such as amino acids, sugars, organic acids, and inorganic salts can contribute to the five different taste sensations and participate in aroma development of beef under heating condition [7]. Therefore, in order to explain the different flavor of dry- and wet-aged beef, several studies compared the flavor compounds of dry- and wet-aged beef [2,8]. Kim et al. [2] reported that dry-aged beef had significantly higher amounts of free amino acids, including glutamic acid and aspartic acid, than those of wet-aged beef. In addition, Lee et al. [8] confirmed that dry aging of beef for 28 days 
showed significantly higher content of free amino acids and reducing sugars than those in wet aging of beef.

As for the aroma, Watanabe et al. [9] and Yang et al. [10] reported that wet aging had an effect on increasing the levels of volatile compounds such as aldehydes and furans as the aging period increased. However, there is little information about aroma volatiles in dry-aged beef, which could be important to understand the characteristics of dry-aged beef flavor and its contributors. From this point of view, the changes in the concentrations of volatile compounds of beef with different aging methods may provide valuable information to elucidate the effect of dry aging on its desirable flavor. Considering the description of flavor in dry- and wet-aged beef from the literature [1,4], we hypothesized that each aging method (dry and wet aging) may have different effects on the formation of aroma volatiles in beef, leading to differences in the change of volatile patterns during the aging process. Therefore, we analyzed the volatile compounds in dry- and wet-aged beef during 28 days of aging.

\section{Materials and Methods}

\subsection{Raw Material and Aging Process}

In this study, 30 beef strip loins (M. longissimus lumborum) from both sides of 15 carcasses (21-month-old Holstein steers, quality grade 2 ) were purchased at $48 \mathrm{~h}$ post-mortem and transferred to a laboratory. The quality grade of the samples was based on the Korean beef grading system [11]. Approximately $500 \mathrm{~g}$ of lean meat was cut from each strip loin, and its initial pH (5.52 \pm 0.01) was measured before aging (SevenGo, Mettler-Toledo, Schwerzenbach, Switzerland). Then, the samples were allocated to dry or wet aging randomly ( $n=15$ for each aging method). For wet aging, the samples were vacuum packaged (HFV-600L, Hankook Fujee Machinery Co., Ltd., Hwaseong, Korea) in low density polyethylene/nylon bags $\left(\mathrm{O}_{2}\right.$ permeability of $2 \mathrm{~mL} / \mathrm{m}^{2} / \mathrm{d}$ at $0{ }^{\circ} \mathrm{C} ; 0.09 \mathrm{~mm}$ thickness; Sunkyung Co., Ltd., Seoul, Korea) and stored at $4{ }^{\circ} \mathrm{C}$, while dry aging was processed at $4{ }^{\circ} \mathrm{C}$, relative humidity of $75 \%$, and air flow velocity of $2.5 \mathrm{~m} / \mathrm{s}$ without any packaging. Both dry and wet aging processes continued for 28 days, and the samples from each group were collected on day $0,7,14,21$, and 28 ( $n=3$ for each aging period). Before sampling, the crust of dry-aged beef (approximately $0.5 \mathrm{~cm}$ from surface) was trimmed off. The beef samples were vacuum packaged and frozen at $-70{ }^{\circ} \mathrm{C}$ until the volatile compound analysis.

\subsection{Volatile Compound Analysis}

Volatile compounds in dry- and wet-aged beef were analyzed by electronic nose (Heracles II, Alpha MOS, Toulouse, France) [8]. The frozen samples were thawed for $12 \mathrm{~h}$ at $4{ }^{\circ} \mathrm{C}$ and ground using a meat grinder (MG510, Kenwood, Hampshire, UK). Then, each sample (5 g) was weighed in a $20 \mathrm{~mL}$ vial and cooked for $10 \mathrm{~min}$ at $80^{\circ} \mathrm{C}$ to obtain the volatile compounds without possible loss in sampling process after cooking. Then, the volatiles were injected into an electronic nose equipped with dual columns of MXT-5 and MXT-1701 $(10 \mathrm{~m} \times 180 \mu \mathrm{m} \times 0.4 \mu \mathrm{m}$; length $\times$ diameter $\times$ thickness $)$ (Restek, Bellefonte, PA, USA). The analytical conditions for volatile compounds are in Table 1. Each peak was integrated and identified using retention time and relevance index indicating the percentage of matching probability, based on the comparison of Kovats retention index of the detected compound and the Kovats retention indices of known compounds from the AroChemBase library (Alpha MOS).

\subsection{Mold Distribution}

Mold distribution on the surface of dry-aged beef was analyzed using photographic imaging software (Adobe Photoshop CC 2015, Adobe, CA, USA) according to Oh et al. [12]. A photo of dry-aged beef illuminated with an LED light (MS-273, Myung Sung, Suwon, Korea) at 108 lx was taken (CMOS 16.0 MP, Samsung Co., Suwon, Korea). Mold distribution was measured by calculating the proportion of pixels over 128 levels in blue channel. 
Table 1. Analytical conditions of electronic nose for volatile compounds in dry- and wet-aged beef strip loins during 28 days of aging.

\begin{tabular}{|c|c|c|}
\hline \multicolumn{2}{|c|}{ Parameter } & \multirow{3}{*}{$\begin{array}{c}\text { Condition } \\
80^{\circ} \mathrm{C} \\
10 \mathrm{~min}\end{array}$} \\
\hline Headspace generation & Incubation temperature & \\
\hline & Incubation time & \\
\hline \multirow[t]{4}{*}{ Trap } & Initial temperature & $40{ }^{\circ} \mathrm{C}$ \\
\hline & Split & $10 \mathrm{~mL} / \mathrm{min}$ \\
\hline & Trapping duration & $30 \mathrm{~s}$ \\
\hline & Final temperature & $240^{\circ} \mathrm{C}$ \\
\hline \multirow[t]{4}{*}{ Injector } & Carrier gas & Hydrogen \\
\hline & Injected volume & $5 \mathrm{~mL}$ \\
\hline & Injected speed & $250 \mu \mathrm{L} / \mathrm{s}$ \\
\hline & Injector temperature & $200^{\circ} \mathrm{C}$ \\
\hline \multirow[t]{4}{*}{ Column } & Column temperature & $40{ }^{\circ} \mathrm{C}$ for $5 \mathrm{~s}$ \\
\hline & & Increased at $0.5^{\circ} \mathrm{C} / \mathrm{s}$, held for $5 \mathrm{~s}$ at $150^{\circ} \mathrm{C}$ \\
\hline & & Increased at $5^{\circ} \mathrm{C} / \mathrm{s}$, held for $30 \mathrm{~s}$ at $260^{\circ} \mathrm{C}$ \\
\hline & Acquisition duration & $282 \mathrm{~s}$ \\
\hline Detector & Type & Flame ionized detector (dual) \\
\hline
\end{tabular}

\subsection{Free Fatty Acids}

Free fatty acid contents in dry- and wet-aged beef were assessed by the method of Lee et al. [3]. Briefly, $1 \mathrm{~g}$ of lipid was put into the test tube with $1 \mathrm{~mL}$ of chloroform and an internal standard (1 $\mathrm{mg}$ of triundecanoate $/ \mathrm{mL}$ isooctane). After removing triglycerides from the samples, free fatty acids were extracted using $2 \%$ acetic acid in diethyl ether. The extract was evaporated with nitrogen gas and heated at $85^{\circ} \mathrm{C}$ for $10 \mathrm{~min}$. After that, $2 \mathrm{~mL}$ of $14 \%$ boron trifluoride-methanol was put into the test tube for methylation and heated at the same condition. Then, $2 \mathrm{~mL}$ of isooctane and $1 \mathrm{~mL}$ of saturated sodium chloride were added into the test tube and centrifuged at $1573 \times g$ for $3 \mathrm{~min}$ (Continent 512R, Hanil Co. Ltd., Daejeon, Korea). The upper layer containing fatty acid methyl ester (FAME) was dehydrated with anhydrous sodium sulfate. FAME was analyzed using gas chromatography (HP 7890, Agilent Technologies, Santa Clara, CA, USA) with a DB-23 column $(60 \mathrm{~m} \times 250 \mu \mathrm{m} \times 0.25 \mu \mathrm{m}$; length $\times$ diameter $\times$ thickness) (Supelco, Bellefonte, PA, USA). Each FAME was identified by comparing the retention time of external standards (Supelco ${ }^{\circledR} 37$ Component FAME mix, Sigma-Aldrich, St. Louis, MO, USA).

\subsection{Statistical Analysis}

All samples for volatile analysis were triplicated, and statistical analysis was performed using SAS 9.4 program (SAS Institute Inc., Cary, NC, USA). The effects of different aging methods on the aroma pattern in volatile changes of beef strip loins were evaluated by two-way analysis of variance, and the model was analyzed with the fixed factors (aging method and aging period) and the random factors (carcass and side of the carcass). Mean values with standard error of the means were reported, and their significant differences were determined by the Student-Newman-Keuls multiple comparison test at a significance level of 0.05 . Principal component analysis (PCA) was performed to discriminate aroma patterns in dry- and wet-aged beef by their volatile compounds. Pearson correlation coefficients between volatile compounds, mold distribution and unsaturated fatty acids of dry- and wet-aged beef were analyzed.

\section{Results}

\subsection{Volatile Profiling of Aged Beef}

A total of 37 volatile compounds in dry- and wet-aged beef were identified during 28 days of aging period (Table 2). They were assigned to the following chemical groups: aldehydes, furans, and ketones $(n=6)$; N-containing compounds $(n=4)$; S-containing 
compounds $(n=3)$; alcohols $(n=4)$; hydrocarbons, esters, and acids $(n=13)$; and others $(n=7)$. There was an aging method $\times$ aging period interaction for all identified volatile compounds ( $p<0.01$ for methyl 2-butenoate and $p<0.0001$ for other compounds) except 4-nonanol $(p=0.22)$.

Table 2. Identified volatile compounds in dry- or wet-aged beef strip loins during 28 days of aging.

\begin{tabular}{|c|c|c|c|c|c|}
\hline No. & Volatile Compound & RT $^{1}$ & $\mathrm{RI}^{2}$ & Aroma Description & $\begin{array}{l}\text { Odor Threshold } \\
\text { (ppm) }\end{array}$ \\
\hline \multicolumn{6}{|c|}{ Aldehydes, furans, and ketones } \\
\hline 1 & (E, E)-2, 4-Hexadienal & 116.86 & 81.10 & Citrus, floral, green, spicy, sweet & $94.8[13]$ \\
\hline 2 & 2-Methylbutanal & 28.30 & 92.02 & Ethereal, nutty, sweet [14] & $1[14]$ \\
\hline 3 & 2-Methylpropanal & 16.39 & 51.36 & Camphor, green, malty, pungent, sharp [15] & $0.7[13]$ \\
\hline 4 & Propanal & 14.13 & 65.50 & Almond, cherry, green, fruity [14] & $25.1[14]$ \\
\hline 5 & Tetrahydrofuran & 21.72 & 93.82 & Aromatic, burnt, fruity, sulfurous, sweet & $92-61,000[16]$ \\
\hline 6 & 3-Heptanone & 87.14 & 90.67 & Fatty, fruity, green, spicy, sweet & 140 [17] \\
\hline \multicolumn{6}{|c|}{$N$-containing compounds } \\
\hline 1 & 1-Butanamine & 25.03 & 85.38 & Ammoniacal, fishy & $170[18]$ \\
\hline 2 & Ethenyl-dimethylpyrazine & 147.23 & 93.75 & Earthy, musty & no reference \\
\hline 3 & 2-Pentylpyridine & 108.94 & 84.18 & Fatty, green, mushroom, pepper, tallowy & 5 [19] \\
\hline 4 & Trimethylamine & 11.10 & 74.73 & $\begin{array}{l}\text { Ammoniacal, fishy, fruity, oily, pungent, rancid, } \\
\text { sweaty }\end{array}$ & $2.4[14]$ \\
\hline \multicolumn{6}{|c|}{ S-containing compounds } \\
\hline 1 & 2-Methyl-2-propanethiol & 17.99 & 88.64 & Sulfurous & $0.33[20]$ \\
\hline 2 & Carbon disulfide & 17.30 & 71.60 & Burnt, cabbage, fruity, sulfurous [15] & $210[18]$ \\
\hline 3 & Dimethyl trisulfide & 101.67 & 85.46 & Alliaceous, cabbage, fishy, meaty, onion, sulfurous & $0.1[14]$ \\
\hline \multicolumn{6}{|c|}{ Alcohols } \\
\hline 1 & 1-Methoxy-2-propanol & 34.76 & 76.18 & Mild & $839-33,000[16]$ \\
\hline 2 & 2-Butanol & 28.35 & 56.68 & Pleasant, strong, sweet, wine & $220[18]$ \\
\hline 3 & 4-Methyl-1-hexanol & 97.21 & 92.13 & Grassy, sweaty, nutty, oily, roasty & $2000[21]$ \\
\hline 4 & 4-Nonanol & 139.31 & 76.28 & Sweet $[21,22]$ & no reference \\
\hline \multicolumn{6}{|c|}{ Hydrocarbons, esters, and acids } \\
\hline 1 & 2, 2-Dichloropropane & 21.81 & 89.93 & no reference & no reference \\
\hline 2 & 3-Methyldecane & 134.73 & 82.85 & Balsamic, mild, phenolic & no reference \\
\hline 3 & 4-Methyldecane & 132.13 & 91.50 & Fatty, fresh, waxy [23] & no reference \\
\hline 4 & Butane & 11.08 & 68.12 & Faint & $1,200,000[18]$ \\
\hline 5 & Ethylcyclopentane & 38.58 & 76.25 & Alkane, fruity, gasoline, sweet & no reference \\
\hline 6 & Heptane & 33.95 & 60.05 & Floral, fruity, sweet & $400,000[24]$ \\
\hline 7 & Octane & 41.04 & 95.87 & Alkane, fruity, sweet, fatty, solvent [15] & $1700[18]$ \\
\hline 8 & Ethyl propanoate & 31.10 & 86.29 & Burnt, fermented, fruity, green, malty, nutty, sour & $0.01[25]$ \\
\hline 9 & Methyl 2-methylbutanoate & 44.63 & 90.84 & Fatty, fruity, green & $0.4[26]$ \\
\hline 10 & Methyl 2-butenoate & 41.36 & 77.98 & Blackcurrant, fruity & no reference \\
\hline 11 & Propyl propanoate & 58.53 & 90.15 & Fruity, green, sweet & $0.88[25]$ \\
\hline 12 & 2-Methylpropanoic acid & 49.12 & 77.12 & Dairy, fatty, pungent, rancid, sour, sweaty & $50[17]$ \\
\hline 13 & Hexanoic acid & 110.28 & 91.42 & Cheesy, fatty, pungent, rancid, sour, sweaty & $3,000,000[27]$ \\
\hline
\end{tabular}


Table 2. Cont.

\begin{tabular}{|c|c|c|c|c|c|}
\hline No. & Volatile Compound & RT $^{1}$ & $\mathrm{RI}^{2}$ & Aroma Description & $\begin{array}{l}\text { Odor Threshold } \\
\text { (ppm) }\end{array}$ \\
\hline \multicolumn{6}{|c|}{ Others } \\
\hline 1 & $\begin{array}{c}\text { 1, 2, 4-Thiadiazole, } \\
\text { 5-ethoxy-3-(trichloromethyl)- }\end{array}$ & 248.10 & 87.34 & Mild & no reference \\
\hline 2 & Demeton-O & 264.10 & 59.09 & no reference & no reference \\
\hline 3 & Diisopropyl ether & 16.83 & 89.64 & Ethereal & no reference \\
\hline 4 & Ethyl chloride & 13.93 & 92.29 & Ethereal, pungent & $3800-379,000[16]$ \\
\hline 5 & Limonene & 125.69 & 78.19 & Citrus, fruity, minty & $38[18]$ \\
\hline 6 & P-cymene & 121.27 & 93.22 & $\begin{array}{l}\text { Citrus, fruity, herbaceous, pleasant, solvent, spicy, } \\
\text { sweet }\end{array}$ & $120[28]$ \\
\hline 7 & Perfluorononane & 9.25 & 87.80 & no reference & no reference \\
\hline
\end{tabular}

\subsubsection{Aldehydes, Furans and Ketones}

Aldehyde contents increased in dry-aged beef, while a decreasing trend during wet aging was observed, with some fluctuations as the aging duration increased (Table 3). From day 14, the dry-aged beef had a significantly higher concentration of total aldehydes compared to those in wet-aged beef. The changes in the contents of aldehydes were affected mainly by propanal, which was predominant in both aging conditions but much higher in dry aging. Dry-aged beef also had significantly higher abundance of 2-methylbutanal than that in wet-aged beef during the whole aging period, and the concentration of 2-methylbutanal was the highest at day 28. The 2-methylpropanal level significantly increased at day 28 in dry-aged beef, whereas it could not be observed in wetaged beef from day 14. (E, E)-2, 4-hexadienal content decreased significantly after 28 days of both dry and wet aging, although the concentrations were relatively small compared to other aldehydes. Propanal is considered an indicator of lipid oxidation [5]. Thus, the difference in propanal content between dry- and wet-aged beef, especially after 14 days, might result from the different susceptibility in the lipid oxidation process. Lipid oxidation is restrained during wet aging, because vacuum packaging prevents the exposure of meat to oxygen [29]. Kahraman and Gurbuz [30] reported that 2-thiobarbituric acid reactive substance values of dry-aged beef were significantly higher than those of wet-aged beef from 14 days of aging, indicating that oxidation of lipid occurred more actively during dry aging. The compounds 2-methylbutanal and 2-methylpropanal can be formed by Strecker degradation of isoleucine and valine, respectively [31]. Kim et al. [32] observed that the levels of tryptophan, phenylalanine, valine, tyrosine, glutamate, isoleucine, and leucine were significantly higher in three-week dry-aged beef compared to wet-aged beef. Lee et al. $[3,8]$ also showed that the concentration of 18 free amino acids, including isoleucine and valine, was significantly higher in dry-aged beef than those in wet-aged beef, mainly due to microbial proteolysis. Therefore, we suggest that higher concentrations of 2-methylbutanal and 2-methylpropanal in dry-aged beef than those in wet-aged beef could be attributed to the higher concentration of isoleucine and valine due to the increased microbial activity during dry aging [8]. It was reported that microbial metabolism favored the production of branched aldehydes in fermented meat products [33]. Aldehydes contribute largely to beef aroma with sweet, floral, salty, and cheesy notes, because they have low odor thresholds [28,34]. Hence, differences in aldehyde content between differently aged beef could play an important role in creating a characteristic aroma.

Furans are odor-active volatiles formed by the oxidation of fatty acids [28]. As shown in Table 3, both types of aging methods increased the concentration of tetrahydrofuran 
with the increase in aging time $(p<0.05)$. Especially, dry-aged beef showed a significantly higher concentration of tetrahydrofuran than that in wet-aged beef after 14 days of aging.

The compound 3-heptanone was only ketone detected in the experiment. Generally, ketones are known as lipid-oxidation products with low odor thresholds [31]. The concentration of 3-heptanone increased after dry aging $(p<0.05)$, and it was higher at days 14 and 21 than in any other periods. On the other hand, it significantly decreased in wet-aged beef at day 7 and disappeared at day 14 and 21. It was detected at day 28 and was significantly lower compared to that in unaged beef.

Table 3. Peak area of aldehydes, furans, and ketones in beef during aging with different aging methods.

\begin{tabular}{|c|c|c|c|c|c|c|c|}
\hline \multirow{2}{*}{ Compound } & \multirow{2}{*}{ Aging Method } & \multicolumn{5}{|c|}{ Aging Period (d) } & \multirow{2}{*}{ SEM $^{1}$} \\
\hline & & 0 & 7 & 14 & 21 & 28 & \\
\hline \multicolumn{8}{|c|}{ Aldehyde } \\
\hline \multirow[t]{3}{*}{ (E, E)-2, 4-Hexadienal } & Dry & $376^{a}$ & $137^{b x}$ & $99^{c}$ & $113^{\text {cy }}$ & $153^{b x}$ & 6.5 \\
\hline & Wet & $376^{\mathrm{a}}$ & 121 by & $94^{\mathrm{c}}$ & $137^{b x}$ & $56^{\text {dy }}$ & 6.7 \\
\hline & $\mathrm{SEM}^{2}$ & 10.5 & 2.9 & 8.8 & 4.1 & 2.5 & \\
\hline \multirow[t]{3}{*}{ 2-Methylbutanal } & Dry & $845^{c}$ & $742^{\mathrm{cx}}$ & $2495^{b x}$ & $1667^{c x}$ & $4503^{a x}$ & 246.9 \\
\hline & Wet & $845^{b}$ & 529 су & $341^{\mathrm{dy}}$ & 639 cy & 1827 ay & 47.8 \\
\hline & $\mathrm{SEM}^{2}$ & 7.8 & 46.1 & 353.7 & 40.5 & 170.9 & \\
\hline \multirow[t]{3}{*}{ 2-Methylpropanal } & Dry & $506^{b}$ & 657 by & $864^{b x}$ & $1077^{b x}$ & $2458^{a x}$ & 309.1 \\
\hline & Wet & $506^{b}$ & $821^{a x}$ & nd ${ }^{c y}$ & nd ${ }^{c y}$ & nd ${ }^{c y}$ & 7.3 \\
\hline & $\mathrm{SEM}^{2}$ & 11.4 & 9.0 & 38.2 & 9.4 & 487.1 & \\
\hline \multirow{3}{*}{ Propanal } & Dry & $17,635^{c}$ & $9067^{d y}$ & $43,508^{a x}$ & $20,185^{c x}$ & $38,743^{b x}$ & 1139.6 \\
\hline & Wet & $17,635^{a}$ & $14,111^{b x}$ & 16,915 ay & 12,344 cy & 14,394 by & 275.4 \\
\hline & SEM $^{2}$ & 300.0 & 663.7 & 676.5 & 838.4 & 1321.1 & \\
\hline \multirow[t]{3}{*}{ Total } & Dry & $19,361^{b}$ & 10,603 су & $46,966^{a x}$ & $23,042 b x$ & 45,857 ax & 1174.5 \\
\hline & Wet & $19,361^{a}$ & $15,582^{c x}$ & 17,349 by & $13,119^{d y}$ & 16,277 cy & 313.7 \\
\hline & SEM $^{2}$ & 296.2 & 683.3 & 1027.0 & 841.9 & 1173.3 & \\
\hline \multicolumn{8}{|c|}{ Furan } \\
\hline \multirow[t]{3}{*}{ Tetrahydrofuran } & Dry & $292^{e}$ & $900^{d}$ & $2143^{c x}$ & $3731^{b x}$ & $6262^{a x}$ & 60.6 \\
\hline & Wet & $292^{e}$ & $960^{d}$ & $1128^{c y}$ & 1399 by & 3068 ay & 21.4 \\
\hline & SEM $^{2}$ & 9.4 & 31.2 & 28.6 & 35.8 & 84.6 & \\
\hline \multicolumn{8}{|c|}{ Ketone } \\
\hline \multirow[t]{3}{*}{ 3-Heptanone } & Dry & $104^{\mathrm{e}}$ & $352 \mathrm{dx}$ & $1237^{b x}$ & $1465^{a x}$ & $675^{c x}$ & 19.4 \\
\hline & Wet & $104^{a}$ & 83 by & nd dy & nd dy & 60 cy & 3.6 \\
\hline & SEM $^{2}$ & 6.6 & 17.4 & 7.3 & 22.6 & 8.0 & \\
\hline
\end{tabular}

${ }^{1}$ Standard error of the mean $(n=15),{ }^{2}(n=6) ;{ }^{\text {aee }}$ Different letters within same row differ significantly $(p<0.05) ;{ }^{x, y}$ Different letters within same column differ significantly $(p<0.05)$; nd, not detected.

\subsubsection{N-Containing Compounds}

Total N-containing compounds were mostly higher in wet-aged beef than those in dry-aged beef until day 21 (Table 4). However, at the end of the aging period, dry-aged beef showed higher concentrations of $\mathrm{N}$-containing compounds than those in wet-aged beef $(p<0.05)$. Except for ethenyl-dimethylpyrazine, the levels of these compounds dramatically increased at the late phase of dry aging (day 21 to 28). During that time, the concentration of 1-butanamine in dry-aged beef increased more than 23-fold. Similarly, the trimethylamine level increased approximately 16-fold from day 21 to 28 . As for 2pentylpyridine, it was detected only at day 28 in dry-aged beef. The formation of amine compounds is usually attributed to the degradation of amino acids due to the decarboxylase activity of microorganisms [35]. Trimethylamine can be produced from the reduction of trimethylamine oxide by microorganisms, and has been widely used for the assessment of microbial activity [14]. The interaction of 2, 4-decadienal with either ammonia or $\alpha$-amino 
group of amino acids is believed to form 2-pentylpyridine [7]. Finally, pyrazines result from the Maillard reaction [5]. Considering the possible origins of the N-containing compounds, it seemed that proteolysis and degradation of amino acids might be the main contributors to the increase in the concentration of these products. Proteolysis is influenced by the action of muscle endogenous enzymes and/or microorganism-origin enzymes [3]. Muscle endogenous proteolytic enzymes are responsible for meat tenderization at the early period of aging; however, their activities decrease as aging duration increases [1]. The activity of aminopeptidases $\mathrm{C}$ and $\mathrm{H}$, which could contribute to the increase in the amount of free amino acids during aging, was the highest at day 4; however, it decreased afterwards and was maintained until day 50 [36]. In this regard, protein degradation at the late period might be related more to microbial enzyme activity than muscle endogenous enzymes [8]. Lee et al. [8] found that the levels of free amino acids and trimethylamine were significantly higher in dry-aged beef at day 28 compared to those in wet-aged beef, indicating that growth of mold and/or yeast on the surface of dry-aged beef might result in further proteolysis. Altogether, change in the concentrations of $\mathrm{N}$-containing compounds at the late phase of aging were highly noticeable, especially in dry-aged beef, and this observation was likely to be associated with different microbial enzyme activities. Differences in the concentration of N-containing compounds in dry- and wet-aged beef could discriminate their aroma characteristics; these compounds are the most important flavor precursors for meaty or beef flavors, with very low odor detection thresholds $[6,10]$.

Table 4. Peak area of N-containing compounds in beef during aging with different aging methods.

\begin{tabular}{|c|c|c|c|c|c|c|c|}
\hline \multirow{2}{*}{ Compound } & \multirow{2}{*}{ Aging Method } & \multicolumn{5}{|c|}{ Aging Period (d) } & \multirow{2}{*}{ SEM $^{1}$} \\
\hline & & 0 & 7 & 14 & 21 & 28 & \\
\hline \multirow[t]{3}{*}{ 1-Butanamine } & Dry & $274^{b}$ & 72 by & $334^{b x}$ & 133 by & $3048^{a x}$ & 62.9 \\
\hline & Wet & $274^{\mathrm{a}}$ & $135^{\mathrm{cx}}$ & $145^{\text {cy }}$ & $218^{b x}$ & $87^{\mathrm{dy}}$ & 5.5 \\
\hline & SEM $^{2}$ & 11.4 & 7.6 & 4.8 & 10.9 & 98.2 & \\
\hline \multirow[t]{3}{*}{ Ethenyl-dimethylpyrazine } & Dry & $443^{b}$ & $751^{a x}$ & $441^{b x}$ & $488^{b x}$ & $507^{b}$ & 41.9 \\
\hline & Wet & $443^{a}$ & 357 by & $246^{c y}$ & 218 cy & $364^{b}$ & 10.1 \\
\hline & SEM $^{2}$ & 6.5 & 42.5 & 20.5 & 7.1 & 48.1 & \\
\hline \multirow[t]{3}{*}{ 2-Pentylpyridine } & Dry & nd ${ }^{b}$ & $\mathrm{nd}^{\mathrm{b}}$ & $\mathrm{nd}^{\mathrm{b}}$ & nd by & $425^{\text {ax }}$ & 1.4 \\
\hline & Wet & nd $^{c}$ & $\mathrm{nd}^{\mathrm{c}}$ & $\mathrm{nd}^{\mathrm{c}}$ & $361^{a x}$ & $188^{\text {by }}$ & 8.4 \\
\hline & SEM $^{2}$ & - & - & - & 1.1 & 13.4 & \\
\hline \multirow[t]{3}{*}{ Trimethylamine } & Dry & $11,806^{\mathrm{b}}$ & $4728^{c}$ & $2045^{d y}$ & $1052 \mathrm{dy}$ & 17,487 ax & 546.6 \\
\hline & Wet & $11,806^{a}$ & $4924^{\mathrm{d}}$ & $6727^{c x}$ & $6949^{c x}$ & 9019 by & 212.8 \\
\hline & SEM $^{2}$ & 110.4 & 611.2 & 145.3 & 232.9 & 631.7 & \\
\hline \multirow[t]{3}{*}{ Total } & Dry & $12,523^{b}$ & $5551^{c}$ & $2820 \mathrm{dy}$ & $1673^{d y}$ & $21,466^{\text {ax }}$ & 605.5 \\
\hline & Wet & $12,523^{a}$ & $5415^{d}$ & $7117^{c x}$ & $7746^{c x}$ & 9658 by & 216.6 \\
\hline & SEM $^{2}$ & 127.4 & 601.9 & 154.1 & 220.4 & 763.5 & \\
\hline
\end{tabular}

${ }^{1}$ Standard error of the mean $(n=15),{ }^{2}(n=6) ;{ }^{a-d}$ Different letters within same row differ significantly $(p<0.05) ;{ }^{x, y}$ Different letters within same column differ significantly $(p<0.05)$; nd, not detected.

\subsubsection{S-Containing Compounds}

Overall, S-containing compound levels increased with time in both aging processes (Table 5). Those concentrations were mostly higher in dry-aged beef from day 14 compared to those in wet-aged beef. The level of 2-methyl-2-propanethiol showed a tendency to increase during dry aging, especially from day 21 to 28 . An exception was carbon disulfide at day 28 , which was more abundant in wet-aged beef. Dimethyl trisulfide generally decreased in both dry- and wet-aged beef, and, eventually, no difference was found between them at the end of the aging period $(p<0.05)$. S-containing compounds originate from the degradation of S-containing amino acids such as methionine, cysteine, and cystine [27] Carbon disulfide and 2-propanethiol can be produced via the Strecker degradation of S-containing amino acids [37]. Dimethyl trisulfide is particularly related to methionine 
degradation [38]. Differences in S-containing compounds between dry- and wet-aged beef might also result from the different occurrence of proteolysis during aging.

Table 5. Peak area of S-containing compounds in beef during aging with different aging methods.

\begin{tabular}{|c|c|c|c|c|c|c|c|}
\hline \multirow{2}{*}{ Compound } & \multirow{2}{*}{ Aging Method } & \multicolumn{5}{|c|}{ Aging Period (d) } & \multirow{2}{*}{ SEM } \\
\hline & & 0 & 7 & 14 & 21 & 28 & \\
\hline \multirow[t]{3}{*}{ 2-Methyl-2-propanethiol } & Dry & $1025^{\mathrm{d}}$ & $875^{d y}$ & $5342^{b x}$ & $2729 \mathrm{cx}$ & $9680^{a x}$ & 142.8 \\
\hline & Wet & $1025^{c}$ & $1644^{\mathrm{ax}}$ & $1015^{\text {cy }}$ & $754^{\mathrm{dy}}$ & 1477 by & 30.6 \\
\hline & SEM $^{2}$ & 41.2 & 24.0 & 193.9 & 76.1 & 87.7 & \\
\hline \multirow[t]{3}{*}{ Carbon disulfide } & Dry & $1174^{\mathrm{d}}$ & $758^{\text {dy }}$ & $4401^{\mathrm{cx}}$ & $5267^{b x}$ & 8403 ay & 168.3 \\
\hline & Wet & $1174 \mathrm{e}^{\mathrm{e}}$ & $3628^{b x}$ & 1523 dy & 1989 су & $9787^{a x}$ & 62.7 \\
\hline & SEM $^{2}$ & 8.4 & 67.6 & 68.2 & 234.8 & 127.1 & \\
\hline \multirow[t]{3}{*}{ Dimethyl trisulfide } & Dry & $122^{a}$ & 125 ay & $138^{\text {ax }}$ & $101^{b x}$ & $79^{c}$ & 4.7 \\
\hline & Wet & $122^{b}$ & $133^{a x}$ & 79 су & 59 еу & $66^{\mathrm{d}}$ & 1.7 \\
\hline & $\mathrm{SEM}^{2}$ & 2.7 & 1.3 & 4.1 & 4.5 & 4.1 & \\
\hline \multirow[t]{3}{*}{ Total } & Dry & $2320^{d}$ & $1758^{d y}$ & $9882^{b x}$ & $8097^{c x}$ & 18,162 ax & 261.7 \\
\hline & Wet & $2320^{\mathrm{e}}$ & $5405^{b x}$ & $2616^{\text {dy }}$ & 2802 cy & 11,330 ay & 49.9 \\
\hline & $\mathrm{SEM}^{2}$ & 32.5 & 63.0 & 223.2 & 300.5 & 179.7 & \\
\hline
\end{tabular}

${ }^{1}$ Standard error of the mean $(n=15),{ }^{2}(n=6) ;{ }^{\text {aee }}$ Different letters within same row differ significantly $(p<0.05) ;{ }^{x, y}$ Different letters within same column differ significantly $(p<0.05)$.

\subsubsection{Alcohols}

Total alcohol contents in dry-aged beef significantly increased with the increase in aging period, whereas those in wet-aged beef decreased from the beginning and then increased after day 14 (Table 6). Therefore, from the early phase of aging period, dryaged beef showed significantly higher alcohol contents than those in wet-aged beef. The increase in alcohol levels in dry-aged beef was mostly attributed to the increase in 2-butanol concentration. It significantly increased during 28 days of dry aging, except for day 7 . Wet-aged beef also showed an increase in 2-butanol concentration with the increase in aging period. However, its change was relatively lower than that in dry aging, resulting in a significantly lower concentration than that in dry aging from day 21. During 28 days of aging period, the concentration of 1-methoxy-2-propanol in dry-aged beef peaked at day 14 and significantly decreased thereafter, but it was still higher than that in wet-aged beef, which gradually decreased and then increased at day 28. Moreover, 4-methyl-1-hexanol was present only when the beef was dry-aged for 14 days or longer. The alcohol 4-nonanol appeared at an earlier time in dry-aged beef than that in wet-aged beef, although no significant differences were found from day 21. Unlike straight-chain alcohols, which generally result from the oxidation of unsaturated fatty acids, 2-butanol and branchedchain alcohols with low molecular weight are produced by microbial fermentation [31]. The significant differences in the levels of 2-butanol, 1-methoxy-2-propanol, and a branchedchain alcohol, 4-methyl-1-hexanol, in dry- and wet-aged beef might imply the effect of different microbial activities on the aroma volatiles of aged beef.

Table 6. Peak area of alcohols in beef during aging with different aging methods.

\begin{tabular}{|c|c|c|c|c|c|c|c|}
\hline \multirow{2}{*}{ Compound } & \multirow{2}{*}{ Aging Method } & \multicolumn{5}{|c|}{ Aging Period (d) } & \multirow{2}{*}{ SEM $^{1}$} \\
\hline & & 0 & 7 & 14 & 21 & 28 & \\
\hline \multirow[t]{3}{*}{ 1-Methoxy-2-propanol } & Dry & $749^{d}$ & $723^{d x}$ & $2532^{a x}$ & $2212^{b x}$ & $1515^{\mathrm{cx}}$ & 36.8 \\
\hline & Wet & $749^{a}$ & 291 by & $106^{c y}$ & $17^{\text {dy }}$ & $316^{\text {by }}$ & 20.7 \\
\hline & SEM $^{2}$ & 33.7 & 37.3 & 24.9 & 17.8 & 31.4 & \\
\hline
\end{tabular}


Table 6. Cont.

\begin{tabular}{|c|c|c|c|c|c|c|c|}
\hline \multirow{2}{*}{ Compound } & \multirow{2}{*}{ Aging Method } & \multicolumn{5}{|c|}{ Aging Period (d) } & \multirow{2}{*}{ SEM } \\
\hline & & 0 & 7 & 14 & 21 & 28 & \\
\hline \multirow[t]{3}{*}{ 2-Butanol } & Dry & $102^{c}$ & nd dy & $891^{\mathrm{C}}$ & $2005^{b x}$ & $5308^{a x}$ & 231.3 \\
\hline & Wet & $102^{d}$ & $146^{\mathrm{dx}}$ & $236^{c}$ & 402 by & 890 ay & 19.1 \\
\hline & SEM $^{2}$ & 3.9 & 4.2 & 280.7 & 41.5 & 232.5 & \\
\hline \multirow[t]{3}{*}{ 4-Methyl-1-hexanol } & Dry & nd $^{d}$ & $\mathrm{nd}^{\mathrm{d}}$ & $120^{\mathrm{cx}}$ & $168^{a x}$ & $131^{b x}$ & 3.2 \\
\hline & Wet & nd & nd & nd ${ }^{y}$ & nd ${ }^{y}$ & nd $\mathrm{y}$ & - \\
\hline & SEM $^{2}$ & - & - & 2.2 & 1.9 & 4.2 & \\
\hline \multirow[t]{3}{*}{ 4-Nonanol } & Dry & $\mathrm{nd}^{\mathrm{c}}$ & $\mathrm{nd}^{\mathrm{c}}$ & $19^{b x}$ & $60^{b}$ & $135^{\mathrm{a}}$ & 14.1 \\
\hline & Wet & $\mathrm{nd}^{\mathrm{c}}$ & $\mathrm{nd}^{\mathrm{c}}$ & nd cy & $60^{b}$ & $177^{\mathrm{a}}$ & 11.0 \\
\hline & SEM $^{2}$ & - & - & 13.2 & 3.3 & 24.9 & \\
\hline \multirow[t]{3}{*}{ Total } & Dry & $850^{d}$ & $723^{d x}$ & $3562^{c x}$ & $4444^{b x}$ & $7089^{a x}$ & 215.8 \\
\hline & Wet & $850^{b}$ & $437^{c y}$ & 342 dy & 479 су & 1382 ay & 28.2 \\
\hline & SEM $^{2}$ & 31.3 & 38.1 & 266.2 & 50.9 & 206.2 & \\
\hline
\end{tabular}

${ }^{1}$ Standard error of the mean $(n=15),{ }^{2}(n=6) ;{ }^{a-d}$ Different letters within same row differ significantly $(p<0.05) ;{ }^{x, y}$ Different letters within same column differ significantly $(p<0.05)$; nd, not detected.

\subsubsection{Hydrocarbons, Esters, and Acids}

We observed a significant increase in total hydrocarbons in aged beef, regardless of the aging method (Table 7). Total hydrocarbon levels were significantly higher in dryaged beef than those in wet-aged beef at days 14 and 21 of aging. When aging duration reached 28 days, however, total hydrocarbon levels were more abundant in wet-aged beef compared to those in beef that had been dry-aged. Levels of 2, 2-dichloropropane and heptane significantly increased during wet aging period and, by the last day of aging, the concentrations of the compounds in wet-aged beef were significantly higher than those in dry-aged beef. On the contrary, butane and octane contents were significantly higher in dryaged beef than those in wet-aged beef during the aging process. The compounds 3- and 4methyldecane and ethylcyclopentane were detected in dry-aged beef only. When compared to the changes in hydrocarbons in dry-aged beef, the higher concentrations in wet-aged beef were not expected because they were believed to be derived mainly from the autoxidation of lipids [38]. As for wet-aged beef, Ma et al. [39] stated that 21 days of postmortem storage hardly affected the changes in levels of volatile compounds, and assumed that lipid oxidation progressed slowly up to three weeks under vacuum conditions. It is hard to explain the significantly higher concentration of 2, 2-dichloropropane in wet-aged beef than that in dry-aged beef. Nonetheless, this would not be the main factor for the distinctive aroma of dry- or wet-aged beef, because hydrocarbons have limited effects on the flavor of meat due to their high odor detection thresholds [40]. Meanwhile, 3- and 4-methyldecane, which appeared only in dry-aged beef, could have been generated by the secondary degradation of triglycerides by the activity of surface molds, possibly indicating the differences in microflora in dry- and wet-aged beef [34].

After 28 days of aging, the concentrations of esters increased in dry-aged beef and decreased in wet-aged beef $(p<0.05)$. During dry aging, a significant increase in ethyl propanoate level was detected from day 14 . Moreover, an approximately six-fold increase in its concentration at day 28 compared to day 0 was observed. In contrast, ethyl propanoate content was significantly lower in wet-aged beef from day 7 to 21 compared to that in unaged beef. Methyl 2-butenoate was present only in dry-aged beef from day 14. Concentrations of propyl propanoate in both dry- and wet-aged beef showed lower values than those in unaged beef, and the content was higher in wet-aged beef at day 28 compared to that in dry-aged beef $(p<0.05)$. Finally, methyl 2-methylbutanoate levels showed significant changes in both dry- and wet-aged beef until day 21, but no significant difference was found between dry- and wet-aged beef at the last day of aging. Esters are produced by the esterification reaction of alcohols and acids and are related to the activity 
of microbial esterase $[27,28]$. Bruna et al. [33] reported that dry sausages inoculated with Penicillium aurantiogriseum had higher levels of esters, while sausages without inoculation had very few ester compounds present. Corral et al. [41] found that Debaryomyces hansenii inoculated into the sausages was responsible for the increase in the levels of ester compounds. Thus, differences in ester contents in dry- and wet-aged beef might indicate differences in metabolic activity of microorganisms affected by different aging methods.

As for acids, significantly higher concentrations of acids were observed in dry-aged beef after 14 days of aging compared to those in wet-aged beef. Generally, acids increased during dry aging, while they significantly decreased after wet aging. Moreover, 2-methylpropanoic acid was found only in dry-aged beef from day 14, and it decreased at day $28(p<0.05)$. Hexanoic acid was not detected in dry-aged beef at day 7 , but its level was significantly higher in dry-aged beef after 14 days compared to that in wet-aged beef. Hexanoic acid can result from lipid oxidation, and 2-methylpropanoic acid can result from the oxidation of 2-methylpropanal [31]. In particular, Casaburi et al. [27] stated that branched-chain fatty acids such as 2- and 3-methylbutanoic acids were observed in aerobically-stored meat, not in vacuum-packaged meat. These compounds accounted for only a small portion of volatile contents in both dry- and wet-aged beef. Nevertheless, acids are regarded as important compounds, which can be used as substrates for the production of esters, strongly affecting the aroma of beef products [38].

Table 7. Peak area of hydrocarbons, esters, and acids in beef during aging with different aging methods.

\begin{tabular}{|c|c|c|c|c|c|c|c|}
\hline \multirow{2}{*}{ Compound } & \multirow{2}{*}{ Aging Method } & \multicolumn{5}{|c|}{ Aging Period (d) } & \multirow{2}{*}{ SEM $^{1}$} \\
\hline & & 0 & 7 & 14 & 21 & 28 & \\
\hline \multicolumn{8}{|c|}{ Hydrocarbon } \\
\hline \multirow[t]{3}{*}{ 2, 2-Dichloropropane } & Dry & $2604^{\mathrm{e}}$ & $4274^{d}$ & $12,837^{b x}$ & $11,361^{\mathrm{c}}$ & 15,398 ay & 319.2 \\
\hline & Wet & $2604^{c}$ & $4931^{c}$ & $5041^{\mathrm{cy}}$ & $7597^{b}$ & 20,477 ax & 659.1 \\
\hline & SEM $^{2}$ & 35.8 & 231.0 & 405.9 & 992.9 & 368.0 & \\
\hline \multirow[t]{3}{*}{ 3-Methyldecane } & Dry & $\mathrm{nd}^{\mathrm{b}}$ & $\mathrm{nd}^{\mathrm{b}}$ & $\mathrm{nd}^{\mathrm{b}}$ & $\mathrm{nd}^{\mathrm{b}}$ & $98^{\text {ax }}$ & 1.2 \\
\hline & Wet & nd & nd & nd & nd & nd $\mathrm{y}$ & - \\
\hline & $\mathrm{SEM}^{2}$ & - & - & - & - & 1.9 & \\
\hline \multirow[t]{3}{*}{ 4-Methyldecane } & Dry & $\mathrm{nd}^{\mathrm{b}}$ & $\mathrm{nd}^{\mathrm{b}}$ & $\mathrm{nd}^{\mathrm{b}}$ & $\mathrm{nd}^{\mathrm{b}}$ & $149^{\text {ax }}$ & 1.7 \\
\hline & Wet & nd & nd & nd & nd & nd y & - \\
\hline & SEM $^{2}$ & - & - & - & - & 2.6 & \\
\hline \multirow[t]{3}{*}{ Butane } & Dry & $251^{d}$ & $316^{b x}$ & $280^{c x}$ & $297^{b c x}$ & $715^{\text {ax }}$ & 8.5 \\
\hline & Wet & $251^{b}$ & $203^{d y}$ & 233 cy & 251 by & 261 ay & 1.7 \\
\hline & SEM $^{2}$ & 1.1 & 2.7 & 0.6 & 2.9 & 13.1 & \\
\hline \multirow[t]{3}{*}{ Ethylcyclopentane } & Dry & nd $^{c}$ & nd $^{c}$ & $799 \mathrm{bx}$ & $1430^{\text {ax }}$ & $1372^{a x}$ & 48.9 \\
\hline & Wet & nd & nd & nd $\mathrm{y}$ & nd $\mathrm{y}$ & nd $^{y}$ & - \\
\hline & SEM $^{2}$ & - & - & 31.7 & 61.9 & 33.9 & \\
\hline \multirow[t]{3}{*}{ Heptane } & Dry & $\mathrm{nd}^{\mathrm{d}}$ & $\mathrm{nd}^{\mathrm{d}}$ & $169^{\text {ax }}$ & 127 cy & 149 by & 6.3 \\
\hline & Wet & nd ${ }^{d}$ & nd ${ }^{d}$ & 28 cy & $1370 \mathrm{bx}$ & $1537^{\text {ax }}$ & 40.5 \\
\hline & SEM $^{2}$ & - & - & 20.5 & 35.4 & 50.2 & \\
\hline \multirow[t]{3}{*}{ Octane } & Dry & $803^{d}$ & $937^{\mathrm{cd}}$ & $998^{c x}$ & $1300^{b x}$ & $1791^{\text {ax }}$ & 44.0 \\
\hline & Wet & $803^{b}$ & $844^{b}$ & $485^{\text {cy }}$ & 967 ay & 602 cy & 36.2 \\
\hline & $\mathrm{SEM}^{2}$ & 60.5 & 44.3 & 18.0 & 14.9 & 44.0 & \\
\hline \multirow[t]{3}{*}{ Total } & Dry & $3658^{d}$ & $5527^{c}$ & $15,083^{b x}$ & $14,515^{b x}$ & 19,671 ay & 340.0 \\
\hline & Wet & $3658^{c}$ & $5978^{c}$ & 5787 cy & 10,184 by & 22,877 ax & 692.2 \\
\hline & SEM $^{2}$ & 58.2 & 265.9 & 426.9 & 1043.7 & 375.7 & \\
\hline
\end{tabular}


Table 7. Cont.

\begin{tabular}{|c|c|c|c|c|c|c|c|}
\hline \multirow{2}{*}{ Compound } & \multirow{2}{*}{ Aging Method } & \multicolumn{5}{|c|}{ Aging Period (d) } & \multirow{2}{*}{ SEM $^{1}$} \\
\hline & & 0 & 7 & 14 & 21 & 28 & \\
\hline \multicolumn{8}{|c|}{ Ester } \\
\hline \multirow[t]{3}{*}{ Ethyl propanoate } & Dry & $1009^{c}$ & $381^{\mathrm{d}}$ & $2854^{b x}$ & $3087^{b x}$ & $6761^{\mathrm{ax}}$ & 107.5 \\
\hline & Wet & $1009^{a}$ & $327^{b}$ & 254 by & 298 by & 829 ay & 73.3 \\
\hline & SEM $^{2}$ & 154.2 & 74.8 & 25.8 & 35.1 & 105.0 & \\
\hline \multirow[t]{3}{*}{ Methyl 2-methylbutanoate } & Dry & $326^{b}$ & $205^{d y}$ & $261^{\mathrm{cx}}$ & $367^{\mathrm{ax}}$ & $358^{a}$ & 7.6 \\
\hline & Wet & $326^{b}$ & $234^{\mathrm{dx}}$ & 202 ey & $280^{\mathrm{cy}}$ & $372^{\mathrm{a}}$ & 8.2 \\
\hline & SEM $^{2}$ & 13.2 & 6.7 & 4.2 & 5.6 & 6.6 & \\
\hline \multirow[t]{3}{*}{ Methyl 2-butenoate } & Dry & $\mathrm{nd}^{\mathrm{b}}$ & $\mathrm{nd}^{\mathrm{b}}$ & $123^{a x}$ & $187^{a x}$ & $158^{\text {ax }}$ & 30.9 \\
\hline & Wet & nd & nd & nd $\mathrm{y}$ & nd $\mathrm{y}$ & nd $\mathrm{y}$ & - \\
\hline & SEM $^{2}$ & - & - & 3.8 & 5.9 & 48.3 & \\
\hline \multirow[t]{3}{*}{ Propyl propanoate } & Dry & $3015^{a}$ & 80 ey & $715^{b x}$ & $322^{d x}$ & 471 cy & 15.1 \\
\hline & Wet & $3015^{a}$ & $380^{c x}$ & $150 \mathrm{dy}$ & $176^{\text {dy }}$ & $1183^{b x}$ & 20.5 \\
\hline & SEM $^{2}$ & 23.4 & 19.9 & 11.9 & 8.0 & 21.6 & \\
\hline \multirow[t]{3}{*}{ Total } & Dry & $4349^{b}$ & $666^{\mathrm{d}}$ & $3953^{c x}$ & $3964^{c x}$ & $7748^{a x}$ & 88.5 \\
\hline & Wet & $4349^{a}$ & $941^{\mathrm{c}}$ & 606 dy & 754 cdy & 2383 by & 65.8 \\
\hline & SEM $^{2}$ & 136.2 & 77.5 & 29.6 & 44.5 & 54.7 & \\
\hline \multicolumn{8}{|c|}{ Acid } \\
\hline \multirow[t]{3}{*}{ 2-Methylpropanoic acid } & Dry & $\mathrm{nd}^{\mathrm{c}}$ & $\mathrm{nd}^{\mathrm{c}}$ & $87^{a x}$ & $82^{a x}$ & $64^{b x}$ & 1.9 \\
\hline & Wet & nd & nd & nd ${ }^{y}$ & nd $\mathrm{y}$ & nd $\mathrm{y}^{\mathrm{n}}$ & - \\
\hline & SEM $^{2}$ & - & - & 2.6 & 1.0 & 1.2 & \\
\hline \multirow[t]{3}{*}{ Hexanoic acid } & Dry & $167^{b}$ & nd $^{c y}$ & $165^{b x}$ & $140^{b x}$ & $248^{\text {ax }}$ & 9.5 \\
\hline & Wet & $167^{\mathrm{a}}$ & 99 bx & nd cy & 108 by & 119 by & 8.7 \\
\hline & SEM $^{2}$ & 15.8 & 6.7 & 5.5 & 5.9 & 7.6 & \\
\hline \multirow[t]{3}{*}{ Total } & Dry & $167^{\mathrm{d}}$ & nd ey & $252^{b x}$ & $222^{c x}$ & $311^{\text {ax }}$ & 8.9 \\
\hline & Wet & $167^{\mathrm{a}}$ & 99 bx & $\mathrm{nd}^{\mathrm{cy}}$ & 108 by & 119 by & 8.7 \\
\hline & SEM $^{2}$ & 15.8 & 6.7 & 4.1 & 5.6 & 6.6 & \\
\hline
\end{tabular}

${ }^{1}$ Standard error of the mean $(n=15),{ }^{2}(n=6) ;{ }^{\text {a-e }}$ Different letters within same row differ significantly $(p<0.05) ;{ }^{x, y}$ Different letters within same column differ significantly $(p<0.05) ;$ nd, not detected.

\subsection{Volatile Patterns of Aged Beef}

The patterns of aroma volatiles in beef sirloin changed with different trends in dry or wet aging (Figure 1a). For wet-aged beef, similar volatile patterns were observed until day 21 , and only day 28 led to relatively distinct volatile patterns compared to those in unaged beef. The effect of wet aging on the development of volatile compounds is controversial. Watanabe et al. [9] observed that wet aging for 30 days significantly increased the levels of oxygen, nitrogen, and sulfur heterocyclic compounds, and concluded that wet aging could affect the flavor of beef. Similarly, Yang et al. [10] found that the levels of volatile compounds (e.g., aldehydes, alkanes, pyrazines, and furans) increased in beef after 14 days of wet aging. In contrast, several studies have documented that a wet aging duration of $2-3$ weeks is not enough for the production of additional volatile compounds [39,40]. In this study, the differentiation in volatile patterns of wet-aged beef was affected mainly by the increase in 2, 2-dichloropropane, carbon disulfide, and tetrahydrofuran levels at the late phase of wet aging (Tables 3, 5 and 7). However, when considering the high odor thresholds (Table 2) of 2, 2-dichloropropane, carbon disulfide, and tetrahydrofuran [18], the aroma of wet-aged beef may not be unique, which is in accordance with Jin and Yim [1]. 


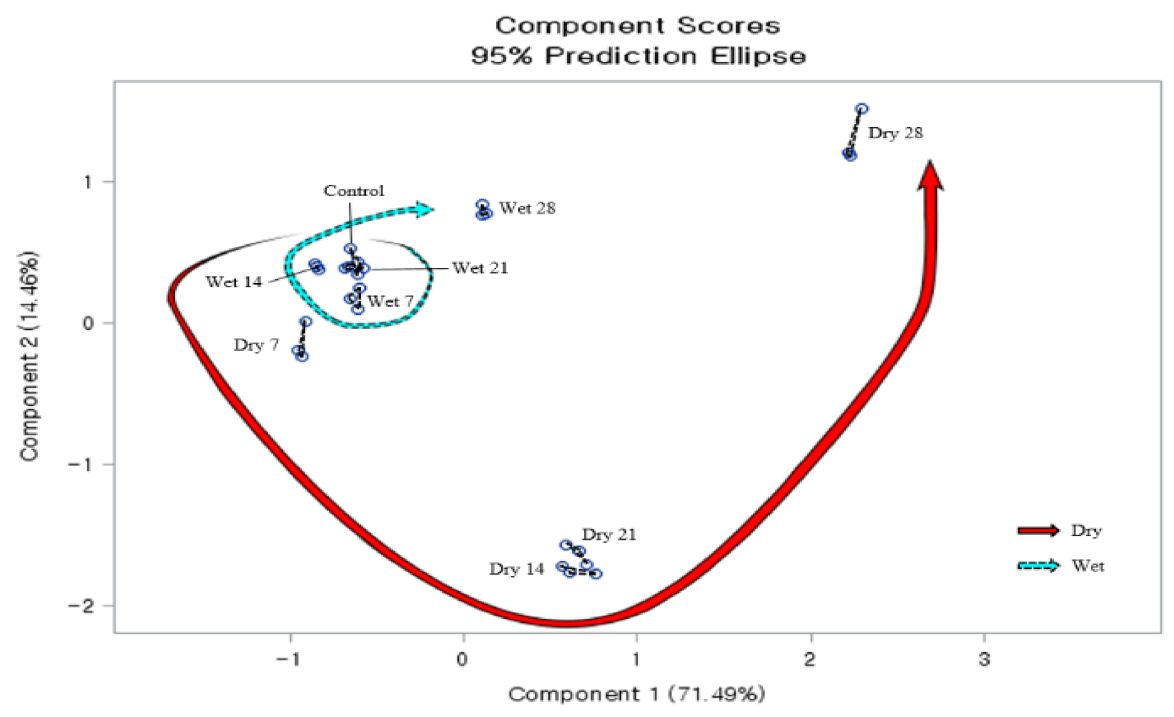

(a)

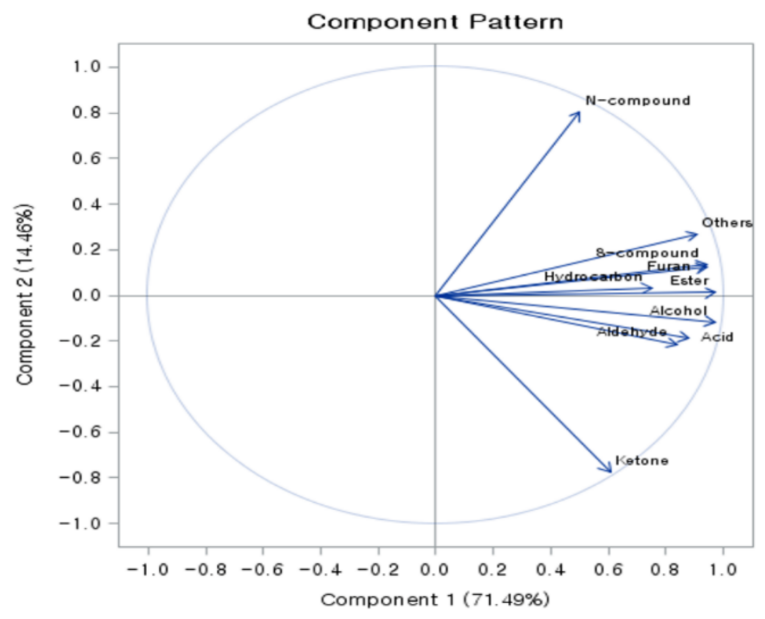

(b)

Figure 1. (a) Principal component analysis score plot; (b) the loading plot for the changes in patterns of aroma volatiles of beef during aging with different aging methods. Red solid-line arrow illustrates the change in aroma patterns in dry-aged beef, and blue dotted-line arrow indicates the change in aroma patterns in wet-aged beef during aging. Unaged beef (control), dry-aged beef (dry), wet-aged beef (wet), $\mathrm{N}$-containing compound (N-compound), and S-containing compound (S-compound).

On the contrary, diverse volatile patterns were observed in beef during dry aging (Figure 1a). From day 14, the aroma pattern of dry-aged beef could be differentiated from those of wet- or unaged beef. Similarly, Lee et al. [8] mentioned that the dry-aged flavor began to be perceived from day 14 to 21 of the aging period, and umami flavors could be intensified by extended aging. We observed an overall increase in the levels of volatile compounds in dry-aged beef, which were much higher than those in wetaged beef. Lipid oxidation may be an important factor for the development of dry-aged flavor, because a large proportion of volatile compounds (e.g., propanal, hydrocarbons, furans, and ketones) derive from lipid oxidation. Among them, aldehydes are known as low odor threshold products, and a higher concentration of propanal in dry-aged beef may be responsible for the dry-aged flavor. Additionally, the PCA loading plot (Figure 1b) showed that 3-heptanone might be relevant to the characteristic volatile pattern from day 14 to 21, when its concentration was higher than in other aging periods. Due 
to 3-heptanone showing relatively low odor threshold values compared to other lipid oxidation-derived products like most hydrocarbons (Table 2), it might be regarded as an important volatile compound among the lipid oxidation-derived products in dry-aged beef. Moreover, the changes in the concentrations of $\mathrm{N}$-containing compounds may be the key for the characteristics of aroma volatiles in dry-aged beef at day 28 , indicating the importance of microbial activity in the formation of the unique dry-aged flavor. Given the low odor threshold values of trimethylamine (Table 2), it might be important for dryaged flavor that the significant increase in trimethylamine was observed in dry-aged beef at day 28. This finding suggests the importance of microbial activity in the formation of the unique dry-aged flavor. Earlier studies have also reported noticeable changes in the levels of flavor compounds at the late phase of dry aging (from day 21 to 28). Lee et al. [8] observed significant increases in levels of flavor compounds of dry-aged beef between day 21 and 28, and explained that further proteolysis and lipolysis associated with microorganisms (especially mold and/or yeast) could develop aroma compounds of dry-aged beef. Oh et al. [42] observed that dry-aged beef inoculated with Pilaira anomala had higher oleic, palmitic, and stearic acid content at day 21, while inoculation with $D$. hansenii resulted in higher amounts of free amino acids at day 28. Finally, the contribution of 2-methylpropanal, 2-methylbutanal, 2-methyl-2-propanethiol, ethyl propanoate, and possibly 2-methylpropanoic acid to dry-aged flavor should be noted when their low odor threshold values (Table 2) and concentration differences between dry- and wetaged beef are taken account (Tables 3, 5 and 7). Particularly, the result that at day 14 of aging or more, 2-methylpropanal and 2-methylpropanoic acid only existed in dry-aged beef indicates the potential key volatile compounds. The rapid increase in the levels of these amino acid-degradation products (e.g., 2-methylbutanal, 2-methylpropanal, and 2-methyl-2-propanthiol) may have resulted from the increase in levels of flavor precursors by microbial metabolism at the late phase of dry aging. Although other compounds such as 2-butanol and tetrahydrofuran showed significantly higher concentrations in dry-aged beef compared to wet-aged beef, for their relatively high odor threshold values, they might act as minor contributors for dry-aged flavor.

\subsection{Correlation Analysis}

It was observed that most lipid oxidation-derived volatile compounds were positively correlated with unsaturated fatty acids in dry-aged beef (Table 8). Especially, there was a strong correlation between aldehydes and unsaturated fatty acids when the beef was dry-aged, mainly influenced by the increase in propanal, which was the most abundant compound in dry-aged beef (Table 3). The increase in mold on the surface of dry-aged beef also had positive correlations with all volatile compound groups, indicating the importance of microbial activity for the formation/increase in aroma volatile compounds at the late phase of dry aging period.

Table 8. Pearson correlation coefficient for volatile compounds in dry- and wet-aged beef with their mold distribution and unsaturated free fatty acid contents.

\begin{tabular}{ccccc}
\hline \multirow{2}{*}{ Chemical Group } & \multicolumn{2}{c}{ Mold Distribution } & \multicolumn{2}{c}{ Unsaturated Fatty Acids } \\
\cline { 2 - 5 } & Dry & Wet & Dry & Wet \\
\hline Acid & $0.63^{*}$ & - & $0.83^{* *}$ & $\mathrm{~ns}$ \\
Alcohol & $0.84^{* * *}$ & - & $0.61^{*}$ & $\mathrm{~ns}$ \\
Aldehyde & $0.59^{*}$ & - & $0.84^{* * *}$ & $-0.71^{* *}$ \\
Ester & $0.81^{* *}$ & - & $0.67^{* *}$ & $\mathrm{~ns}$ \\
Furan and ketone & $0.78^{* *}$ & - & $\mathrm{ns}$ & $\mathrm{ns}$ \\
Hydrocarbon & $0.71^{* *}$ & - & $0.63^{*}$ & $\mathrm{~ns}$ \\
N-compound & $0.80^{* *}$ & - & $\mathrm{ns}$ & $\mathrm{ns}$ \\
S-compound & $0.87^{* * *}$ & - & $0.62^{*}$ & $\mathrm{~ns}$ \\
\hline
\end{tabular}

Mold distribution was conducted for dry-aged beef only, because no mold growth was shown in wet-aged beef; ${ }^{*}, p<0.05 ;{ }^{* *}, p<0.01 ; * * *, p<0.0001 ;$ ns, not significant $(p>0.05)$. 
As we hypothesized, dry and wet aging led to distinct volatile composition and patterns of beef, showing the different effect on the formation of aroma volatiles. Lipid oxidation and microbial activity might play a role as flavor contributors in aged beef, and their influences were more noticeable in dry-aged beef than wet-aged beef.

\section{Conclusions}

Dry-aged beef showed significantly higher concentrations of volatile compounds, with more distinctive changes than those in wet-aged beef. This was mainly attributed to: (i) propanal known to be generated from the oxidation of lipids; and (ii) 2-methylbutanal, 2methylpropanal, 1-butanamine, trimethylamine, 2-methylpropanthiol, and ethyl propanoate, possibly derived from the metabolism of microorganisms. Based on the results, the formation of aroma volatiles responsible for the unique flavor in dry-aged beef, clearly separated from wet-aged counterpart, may be induced by lipid oxidation and microbial activity.

Author Contributions: Conceptualization, C.J. and H.J.L.; methodology, H.J.L. and J.W.Y.; software, D.L. and H.J.L.; validation, H.J.L.; formal analysis, D.L., J.W.Y. and M.K.; investigation, H.J.L., J.W.Y. and M.K.; resources, H.J.L.; data curation, D.L. and H.J.L.; writing-original draft preparation, D.L. and H.J.L.; writing—review and editing, C.J.; visualization, D.L.; supervision, C.J.; project administration, C.J.; funding acquisition, C.J. All authors have read and agreed to the published version of the manuscript.

Funding: This research was funded by the National Research Foundation of Korea (NRF); grant funded by the Korea government (MIST) (No. 2019R111A1A01061999). Additionally, this work was supported by the BK21 Four Program of the Department of Agricultural Biotechnology, Seoul National University, Seoul, Korea.

Institutional Review Board Statement: Not applicable.

Informed Consent Statement: Not applicable.

Data Availability Statement: Not applicable.

Acknowledgments: The volatile analysis by electronic nose was conducted with the support of Centumtech (Seoul, Korea).

Conflicts of Interest: The authors declare no conflict of interest.

\section{References}

1. Jin, S.K.; Yim, D.G. Comparison of effects of two aging methods on the physicochemical traits of pork loin. Food Sci. Anim. Resour. 2020, 40, 844-851. [CrossRef] [PubMed]

2. Kim, J.H.; Kim, D.H.; Ji, D.S.; Lee, H.J.; Yoon, D.K.; Lee, C.H. Effect of aging process and time on physicochemical and sensory evaluation of raw beef top round and shank muscles using an electronic tongue. Korean J. Food Sci. Anim. Resour. 2017, 37, 823-832. [PubMed]

3. Lee, H.J.; Yoon, J.W.; Kim, M.; Oh, H.; Yoon, Y.; Jo, C. Changes in microbial composition on the crust by different air flow velocities and their effect on sensory properties of dry-aged beef. Meat Sci. 2019, 153, 152-158. [CrossRef] [PubMed]

4. Kim, M.; Choe, J.; Lee, H.J.; Yoon, Y.; Yoon, S.; Jo, C. Effects of aging and aging method on physicochemical and sensory traits of different beef cuts. Food Sci. Anim. Resour. 2019, 39, 54-64. [CrossRef] [PubMed]

5. Ba, H.V.; Hwang, I.; Jeong, D.; Touseef, A. Principle of meat aroma flavors and future prospect. In Latest Research into Quality Control; Akyar, I., Ed.; InTech: Rijeka, Croatia, 2012; pp. 146-176.

6. Aaslyng, M.D.; Meinert, L. Meat flavor in pork and beef-From animal to meal. Meat Sci. 2017, 132, 112-117. [CrossRef] [PubMed]

7. Mottram, D.S. Flavour formation in meat and meat products: A review. Food Chem. 1998, 62, 415-424. [CrossRef]

8. Lee, H.J.; Choe, J.; Kim, M.; Kim, H.C.; Yoon, J.W.; Oh, S.W.; Jo, C. Role of moisture evaporation in the taste attributes of dry- and wet-aged beef determined by chemical and electronic tongue analyses. Meat Sci. 2019, 151, 82-88. [CrossRef]

9. Watanabe, A.; Kamada, G.; Imanari, M.; Shiba, N.; Yonai, M.; Muramoto, T. Effect of aging on volatile compounds in cooked beef. Meat Sci. 2015, 107, 12-19. [CrossRef]

10. Yang, J.; Dashdorj, D.; Hwang, I. Volatile flavor components as a function of electrical stimulation and chiller aging for $m$. longissimus and biceps femoris of Hanwoo beef. Food Sci. Anim. Resour. 2019, 39, 474-493. [CrossRef]

11. Chung, K.Y.; Lee, S.H.; Cho, S.H.; Kwon, E.G.; Lee, J.H. Current situation and future prospects for beef production in South Korea-A review. Asian-Australas. J. Anim. Sci. 2018, 31, 951-960. [CrossRef]

12. Oh, J.; Lee, H.J.; Yoon, J.W.; Choe, J.; Jo, C. Electrical resistance and mold distribution on beef surface as indicators of dry aging. J. Food Process Eng. 2019, 42, e13122. [CrossRef] 
13. Zhu, J.; Chen, F.; Wang, L.; Niu, Y.; Xiao, Z. Evaluation of the synergism among volatile compounds in Oolong tea infusion by odour threshold with sensory analysis and E-nose. Food Chem. 2017, 221, 1484-1490. [CrossRef] [PubMed]

14. Wu, W.; Tao, N.P.; Gu, S. Characterization of the key odor-active compounds in steamed meat of Coilia ectenes from Yangtze River by GC-MS-O. Eur. Food Res. Technol. 2014, 238, 237-245. [CrossRef]

15. Madruga, M.S.; Elmore, J.S.; Oruna-Concha, M.J.; Balagiannis, D.; Mottram, D.S. Determination of some water-soluble aroma precursors in goat meat and their enrolment on flavour profile of goat meat. Food Chem. 2010, 123, 513-520. [CrossRef]

16. American Industrial Hygiene Association. Odor Thresholds for Chemicals with Established Occupational Health Standards, 2nd ed.; American Industrial Hygiene Association: Fairfax, VA, USA, 1989; pp. 14-28.

17. Keatkrai, J.; Jirapakkul, W. Volatile profile of khanom jeen, Thai fermented rice noodles, and the changes during the fermentation process. Sci. Asia 2010, 36, 46-51. [CrossRef]

18. Nagata, Y. Measurement of Odor Threshold by Triangle Odor Bag Method. Japan Environmental Sanitation Center; Retrieved; February 2010. Available online: http://www.env.go.jp/en/air/odor/olfactory_mm/04ref_2.pdf (accessed on 14 December 2020).

19. Hou, L.; Zhang, Y.; Wang, X. Characterization of the volatile compounds and taste attributes of sesame pastes processed at different temperatures. J. Oleo Sci. 2019, 68, 551-558. [CrossRef]

20. Giannoukos, S.; Brkić, B.; Taylor, S. Direct analysis and monitoring of organosulphur compounds in the gaseous phase using portable mass spectrometry. Anal. Methods 2019, 11, 4882-4889. [CrossRef]

21. Dregus, M.; Engel, K.H. Volatile constituents of uncooked rhubarb (Rheum rhabarbarum L.) stalks. J. Agric. Food Chem. 2003, 51, 6530-6536. [CrossRef]

22. Saini, R.; Jaitak, V.; Guleria, S.; Kaul, V.K.; Kiran Babu, G.D.; Singh, B.; Lal, B.; Singh, R.D. Comparison of headspace analysis of volatile constituents with GCMS analysis of hydrodistilled and supercritical fluid extracted oil of Capillipedium parviflorum. J. Essent. Oil Res. 2012, 24, 315-320. [CrossRef]

23. Yu, H.; Seow, Y.X.; Ong, P.K.; Zhou, W. Effects of ultrasonic processing and oil type on Maillard reaction of D-glucose and L-alanine in oil-in-water systems. Food Bioproc. Tech. 2019, 12, 325-337. [CrossRef]

24. Wojnowski, W.; Majchrzak, T.; Dymerski, T.; Gebicki, J.; Namieśnik, J. Poultry meat freshness evaluation using electronic nose technology and ultra-fast gas chromatography. Monatsh. Chem. 2017, 148, 1631-1637. [CrossRef] [PubMed]

25. Niu, Y.; Wang, R.; Xiao, Z.; Zhu, J.; Sun, X.; Wang, P. Characterization of ester odorants of apple juice by gas chromatographyolfactometry, quantitative measurements, odour threshold, aroma intensity and electronic nose. Food Res. Int. 2019, 120, 92-101. [CrossRef] [PubMed]

26. Blank, I.; Sen, A.; Grosch, W. Sensory study on the character-impact flavour compounds of dill herb (Anethum graveolens L.). Food Chem. 1992, 43, 337-343. [CrossRef]

27. Casaburi, A.; Piombino, P.; Nychas, G.J.; Villani, F.; Ercolini, D. Bacterial populations and the volatilome associated to meat spoilage. Food Microbiol. 2015, 45, 83-102. [CrossRef]

28. Ozkara, K.T.; Amanpour, A.; Guclu, G.; Kelebek, H.; Selli, S. GC-MS-Olfactometric differentiation of aroma-active compounds in turkish heat-treated sausages by application of aroma extract dilution analysis. Food Anal. Methods 2019, 12, 729-741. [CrossRef]

29. Kim, S.; Lee, H.J.; Kim, M.; Yoon, J.W.; Shin, D.J.; Jo, C. Storage stability of vacuum-packaged dry-aged beef during refrigeration at $4{ }^{\circ}$ C. Food Sci. Anim. Resour. 2019, 39, 266-275. [CrossRef]

30. Kahraman, H.A.; Gurbuz, U. Effects of three aging methods on the Longissimus lumborum muscle from Holstein-Friesian steers. Med. Weter. 2019, 75, 179-184. [CrossRef]

31. Muriel, E.; Antequera, T.; Petrón, M.J.; Andrés, A.I.; Ruiz, J. Volatile compounds in Iberian dry-cured loin. Meat Sci. 2004, 68, 391-400. [CrossRef]

32. Kim, Y.H.B.; Kemp, R.; Samuelsson, L.M. Effects of dry-aging on meat quality attributes and metabolite profiles of beef loins. Meat Sci. 2016, 111, 168-176. [CrossRef]

33. Bruna, J.M.; Hierro, E.M.; de la Hoz, L.; Mottram, D.S.; Fernández, M.; Ordóñez, J.A. The contribution of Penicillium aurantiogriseum to the volatile composition and sensory quality of dry fermented sausages. Meat Sci. 2001, 59, 97-107. [CrossRef]

34. Domínguez, R.; Purriños, L.; Pérez-Santaescolástica, C.; Pateiro, M.; Barba, F.J.; Tomasevic, I.; Campagnol, P.C.B.; Lorenzo, J.M. Characterization of volatile compounds of dry-cured meat products using HS-SPME-GC/MS technique. Food Anal. Methods 2019, 12, 1263-1284. [CrossRef]

35. Iucci, L.; Patrignani, F.; Belletti, N.; Ndagijimana, M.; Guerzoni, M.E.; Gardini, F.; Lanciotti, R. Role of surface-inoculated Debaryomyces hansenii and Yarrowia lipolytica strains in dried fermented sausage manufacture. Part 2: Evaluation of their effects on sensory quality and biogenic amine content. Meat Sci. 2007, 75, 669-675. [CrossRef] [PubMed]

36. Iida, F.; Miyazaki, Y.; Tsuyuki, R.; Kato, K.; Egusa, A.; Ogoshi, H.; Nishimura, T. Changes in taste compounds, breaking properties, and sensory attributes during dry aging of beef from Japanese black cattle. Meat Sci. 2016, 112, 46-51. [CrossRef] [PubMed]

37. Sekhon, R.K.; Schilling, M.W.; Phillips, T.W.; Aikins, M.J.; Hasan, M.M.; Corzo, A.; Mikel, W.B. Effects of phosphine and methyl bromide fumigation on the volatile flavor profile and sensory quality of dry cured ham. Meat Sci. 2010, 86, 411-417. [CrossRef] [PubMed]

38. Flores, M. Understanding the implications of current health trends on the aroma of wet and dry cured meat products. Meat Sci. 2018, 144, 53-61. [CrossRef] 
39. Ma, Q.L.; Hamid, N.; Bekhit, A.E.D.; Robertson, J.; Law, T.F. Evaluation of pre-rigor injection of beef with proteases on cooked meat volatile profile after 1 day and 21 days post-mortem storage. Meat Sci. 2012, 92, 430-439. [CrossRef] [PubMed]

40. Maggiolino, A.; Lorenzo, J.M.; Marino, R.; Della Malva, A.; Centoducati, P.; De Palo, P. Foal meat volatile compounds: Effect of vacuum ageing on semimembranosus muscle. J. Sci. Food Agric. 2019, 99, 1660-1667. [CrossRef]

41. Corral, S.; Belloch, C.; López-Díez, J.J.; Flores, M. Lipolysis and aroma generation as mechanisms involved in masking boar taint in sodium reduced fermented sausages inoculated with Debaryomyces hansenii yeast. J. Sci. Food. Agric. 2018, 98, 2121-2130. [CrossRef]

42. Oh, H.; Lee, H.J.; Lee, J.; Jo, C.; Yoon, Y. Identification of microorganisms associated with the quality improvement of dry-aged beef through microbiome analysis and DNA sequencing, and evaluation of their effects on beef quality. J. Food Sci. 2019, 84, 2944-2954. [CrossRef] 